\title{
Air quality assessment of the Tobacco Heating System 2.2 under simulated residential conditions
}

\author{
Maya I. Mitova ${ }^{1}$ (D) - Noel Bielik ${ }^{1} \cdot$ Pedro B. Campelos $^{1} \cdot$ Camille Cluse $^{1} \cdot$ Catherine G. Goujon-Ginglinger $^{1}$. \\ Anne Jaquier ${ }^{1}$ - Maria Gomez Lueso ${ }^{1} \cdot$ Serge Maeder $^{1} \cdot$ Chantal Pitton $^{1} \cdot$ Laurent Poget $^{1} \cdot$ Josée Polier-Calame ${ }^{1}$. \\ Michel Rotach ${ }^{1}$ - Emmanuel G. R. Rouget ${ }^{1} \cdot$ Mathieu Schaller ${ }^{1} \cdot$ Manuel Tharin $^{1} \cdot$ Vladimir Zaugg $^{1}$
}

Received: 15 February 2019 / Accepted: 5 April 2019 / Published online: 27 April 2019

(C) The Author(s) 2019

\begin{abstract}
Despite the growing popularity of new alternatives to traditional tobacco products, there is still limited evidence on their indoor effect in particular in residential spaces as specific environments where enforcement of air quality standards is difficult. Hence, the impact of the Tobacco Heating System 2.2 (THS, marketed as IQOS®) on indoor air quality was assessed under controlled experimental conditions using ventilation representative of residential buildings with natural ventilation. Smoking of cigarettes (Marlboro Gold $®$ ) at the same ventilation conditions and consumption rates was used as positive control. Before each THS 2.2 or Marlboro Gold session, a background session with the same volunteers as for the product-use session was held. In the high-load simulated residential environment, out of the 24 measured airborne constituents, only the increase of the indoor concentrations of nicotine, acetaldehyde, and glycerin above the background was attributable to the use of THS 2.2. The quantified concentrations of these three airborne compounds were significantly below the harmful levels defined in the air quality guidelines. Smoking Marlboro Gold resulted in much greater increases in the concentrations of all measured indoor air constituents, except for glycerin, and the indoor concentrations of several constituents exceeded the exposure levels set forth by cognizant authorities. Based on these data, it is reasonable to conclude that the use of THS 2.2 in environments where norms for indoor exposure in terms of adequate ventilation are respected does not adversely affect the overall indoor air quality.
\end{abstract}

Keywords Indoor air quality $\cdot$ Nicotine $\cdot$ Carbonyls $\cdot$ Volatile organic compounds $\cdot$ Suspended particulate matter

\section{Introduction}

A global decline in the rate of cigarette smoking has been observed in recent years. However, this has not translated into a smaller number of smokers. Indeed, even if the proportion of the population that smokes has declined, the number of smokers has not, the latter being explained by the overall population growth (World Health Organization 2017). In fact, in 2007, there were 1.1 billion smokers in the world, and this number did not change by 2015 (World Health Organization 2017). Recognizing this, the strategy of tobacco harm

Electronic supplementary material The online version of this article (https://doi.org/10.1007/s11869-019-00697-6) contains supplementary material, which is available to authorized users.

Maya I. Mitova

maya.mitova@pmi.com

1 PMI R\&D, Philip Morris Products S.A., Quai Jeanrenaud 5, CH-2000 Neuchâtel, Switzerland reduction, making less harmful products available to smokers who would otherwise continue to smoke, is being given serious consideration by some regulators (Royal College of Physicians 2016).

In the last decades, new alternatives to traditional tobacco products have been introduced to the market. These include smokeless tobacco, e-cigarettes, heated tobacco products, hybrid systems, and tobacco vapor products (Ichitsubo and Kotaki 2018; Royal College of Physicians 2016; Smith et al. 2016).

The Tobacco Heating System (THS, marketed under the IQOS brand name) 2.2 (Supplementary Fig. S1) uses an electronically controlled mechanism to precisely heat the specially designed tobacco sticks at temperatures below those required for combustion (Smith et al. 2016). As a result, the aerosol generated by THS 2.2 contains significantly lower levels of harmful and potentially harmful compounds (HPHC) than those found in cigarette smoke and no carbon-based solid particles (Bekki et al. 2017; Mallock et al. 2018; Pratte et al. 2017; Schaller et al. 2016). An extensive scientific assessment 
program has shown that compared with reference cigarettes, this is reflected in reduced cytotoxicity, in vitro genotoxicity, and mutagenicity, lower in vivo adverse effects in animal models (Smith et al. 2016). It also results in a significantly reduced exposure to HPHCs, excluding nicotine, in adult smokers switching from cigarette consumption to THS 2.2 (Smith et al. 2016).

When assessing THS 2.2, it is important not only to study the effect on actual users but also to determine whether there could be a possible impact on potential bystanders. One way to assess this is to evaluate whether the indoor use of the product could have a measurable effect on air quality.

To enhance understanding of the environmental aerosol of THS 2.2, an overview of the available information on environmental tobacco smoke (ETS or secondhand smoke) of cigarettes is necessary.

ETS is recognized as a contributor to indoor air pollution, negatively affecting indoor air quality (IAQ) (Pope et al. 2010; van Erp et al. 2011). ETS is an aged and diluted mixture of sidestream smoke emitted from the lit end of a smoldering cigarette and exhaled mainstream smoke from the smoker (Baker and Proctor 1990; Jenkins et al. 2000). The exhaled mainstream smoke contributes $3-11 \%$ of carbon monoxide (CO), $15-43 \%$ of particles, and $1-9 \%$ of nicotine to ETS (Baker and Proctor 1990). In addition, cigarette smoke spilled from the mouth prior to inhalation (mouth-spill) may also contribute to ETS (Jenkins et al. 2000).

In general, the same constituents as in mainstream and sidestream smoke are present in ETS, although diluted and mixed with constituents in ambient air (Baker and Proctor 1990; Jenkins et al. 2000). Sidestream smoke, the major contributor to ETS, is slightly more alkaline than mainstream smoke and contains greater quantities of ammonia and bases. Exhaled mainstream smoke is the second largest contributor to ETS; it is important to highlight that the quantities of nicotine and volatile compounds present in such smoke are substantially lower than those present in the inhaled mainstream smoke, since a large proportion of these substances are retained by the smoker after inhalation (Baker and Proctor 1990; Jenkins et al. 2000). The complex mixture of particles and gas-vapor-phase components of ETS is rapidly diluted and dispersed after emission into the indoor environment and undergoes changes in its physicochemical properties due to shifts in vapor-particle distributions, sorption and desorption of vapor-phase components on indoor surfaces, and chemical reactions, the latter being poorly investigated (Daisey 1999). Thus, ETS has different physicochemical properties to those of mainstream and sidestream smoke. As a consequence of evaporation, the median particle size of ETS is smaller than that of mainstream smoke, and most of the smoke constituents are found in the vapor phase (Baker and Proctor 1990; Jenkins et al. 2000). In particular, nicotine is almost entirely contained in the vapor phase of ETS as opposed to its occurrence in the particulate phase of mainstream and sidestream smoke (Baker and Proctor 1990).

Previous studies have shown that the environmental aerosols emitted by heated tobacco products have much less impact on an indoor environment than ETS generated by smoking cigarettes (Forster et al. 2018; Frost-Pineda et al. 2008; Ichitsubo and Kotaki 2018; Mitova et al. 2016; Nelson et al. 1998; Prodanchuk et al. 2017; Protano et al. 2016, 2017; Ruprecht et al. 2017; Schober et al. 2018; Tricker et al. 2009). This is to be expected, because on the one hand, the aerosol formation of the heated tobacco products does not involve tobacco combustion or high-temperature pyrolysis, leading in turn to a significant reduction in the generation of HPHCs. On the other hand, by design, the electrically heated tobacco products do not have a smoldering tipreleasing sidestream smoke formed by combustion of tobacco, thus omitting the main contributors to indoor pollution caused by cigarettes.

The assessment of Nelson et al. (1998) on carbon tip heat source tobacco prototypes showed that the ETS markers were reduced by at least $80 \%$ compared with the ETS of commercial cigarettes, with the exception of $\mathrm{CO}$, which was reduced by $11-30 \%$. Studies investigating electrically heated cigarette smoking systems (EHCSS), predecessors of the current THS 2.2, demonstrated a substantial reduction for most air constituents and ETS markers compared with cigarette smoking (Frost-Pineda et al. 2008; Tricker et al. 2009). Thus, the environmental aerosol evaluations of early generations of EHCSS showed gas-phase markers ( $\mathrm{CO}$, total volatile organic compounds [TVOC], 3-ethenylpyridine) similar to non-smoking levels, while ammonia concentrations were reduced by $40 \%$, and the concentrations of particulate-phase markers were more than $90 \%$ below those of cigarettes (Frost-Pineda et al. 2008). A study conducted under simulated "Office" and "Hospitality" environments revealed that 24 out of 29 measured smoke constituents had mean reductions greater than $90 \%$, and 5 smoke constituents had mean reductions between 80 and $90 \%$ in experiments with EHCSS compared with cigarettes (Tricker et al. 2009).

In a comprehensive assessment of THP 1.0 (marketed under the Glo® brand name) use in "Office," "Hospitality," and "Residential" simulations, Forster et al. (2018) reported most of the 40 analyzed constituents below detectable or at baseline levels, except for nicotine, acetaldehyde, formaldehyde, and PM, whose levels were typically more than $90 \%$ lower than those of cigarette smoke.

In another comprehensive study, Ichitsubo and Kotaki (2018) investigated the impact of using a novel tobacco vapor product (NTV, marketed under the Ploom Tech ${ }^{\circledR}$ brand name) on IAQ in an environmentally controlled chamber under simulated non-smoking environments ("Conference Room" and "Dining Room") and one ventilated smoking environment ("Smoking Lounge"). All 16 measured markers were either 
below the quantification limits of the methods or at background levels, leading to the conclusion that under the simulations tested, the NTV product had no measurable effect on IAQ, in either non-smoking or smoking areas.

The air quality during indoor use of THS 2.2 was investigated recently in model environments with limited control of the environmental parameters (Prodanchuk et al. 2017; Protano et al. 2016, 2017; Ruprecht et al. 2017), in simulated environments using an environmentally controlled room (Mitova et al. 2016), and in real-life environments (car interiors) (Schober et al. 2018). Different air pollutants were investigated under different ventilation conditions and frequency of product use. All studies demonstrated substantially lower emissions of toxic compounds in indoor air compared with cigarettes.

In our previous study evaluating the air quality during indoor use of THS 2.2 under simulated "Office," "Hospitality," and "Residential" environments, the concentrations of 16 of the 18 constituents studied did not exceed the background concentrations determined when non-smoking panelists were present in the environmentally controlled room under equivalent conditions (Mitova et al. 2016). Only acetaldehyde and nicotine concentrations increased above background concentrations in all studied simulations with THS 2.2. In contrast, in all simulations, the smoking of Marlboro Gold resulted in significant increases in the concentrations of all measured air constituents.

Aiming to further evaluate the impact of THS 2.2 on IAQ, this study was performed under a low ventilation representative of residential environments with natural ventilation (European Committee for Standardization 2007). This ventilation corresponds to moderate levels of expectations of the occupants (expected 30\% percent of dissatisfaction) and may be used for existing buildings (European Committee for Standardization 2007). The concentrations of representative particulate and gas-vaporphase ETS constituents (Jenkins et al. 2000), productspecific compounds (Schaller et al. 2016), and air quality markers were measured during indoor use of the regular (non-menthol) THS 2.2 versus background air. Cigarette smoking (Marlboro Gold) was used as a positive control. In addition to the list of air constituents assessed during the previous study (Mitova et al. 2016), namely non-specific particulate-phase markers (ultraviolet PM (UVPM), fluorescent PM (FPM)), particulate-phase tobacco-specific marker (solanesol), gas-phase tobacco-specific markers (3-ethenylpyridine, nicotine), volatile organic compounds (VOC: acrylonitrile, benzene, 1,3-butadiene, isoprene, toluene), low-molecular-weight carbonyls (acetaldehyde, acrolein, crotonaldehyde, formaldehyde), and gases (CO, nitrogen oxide $(\mathrm{NO})$, combined oxides of nitrogen $\left(\mathrm{NO}_{\mathrm{x}}\right)$ ), six additional air constituents were measured. These additional analytes were TVOC, nicotine-derived nitrosamine ketone (NNK), $N$-nitrosonornicotine (NNN), glycerin, propylene glycol, and online measurement of PM (PM $1 \mu \mathrm{m}$ $\left(\mathrm{PM}_{1}\right)$ and PM $\left.2.5 \mu \mathrm{m}\left(\mathrm{PM}_{2.5}\right)\right)$. The online measurement of PM replaced the respirable suspended particles gravimetric measurement. The air constituents investigated during this study included compounds from the abbreviated U.S. Food and Drug Administration list of HPHCs (Food and Drug Administration 2012), compounds from the World Health Organization (WHO) priority list of toxicants (World Health Organization 2014), constituents with relevance for air quality, and product-specific markers (Supplementary Table S1).

\section{Materials and methods}

\section{Study design}

A scenario representing a "Residential category III" environment was simulated in a walk-in environmentally controlled room (size $24.1 \mathrm{~m}^{2}, 72.3 \mathrm{~m}^{3}$ ) equipped with an air lock (Supplementary Fig. S2). The occupant density was set at $8 \mathrm{~m}^{2} /$ person (two volunteer panelists and one Philip Morris International (PMI) staff member). The ventilation rate of $37 \mathrm{~m}^{3} / \mathrm{h}(0.5$ air changes $/ \mathrm{h})$ was based on the European ventilation performance standard EN 15251 (European Committee for Standardization 2007). The simulation conditions were used to compare the IAQ when panelists used either the THS 2.2 or when they smoked Marlboro Gold, to the background levels. All experiments lasted $2 \mathrm{~h}$ during which the panelists first remained in the environmentally controlled room without any test product consumption (background session). Then, following a 60 min break, the panelists returned to the room and used the test products (either THS 2.2 or Marlboro Gold) according to a pre-defined time schedule (product-use session). Panelist 1 started to use the test product immediately at the beginning of the assessment period $(t=0 \mathrm{~min})$ and used a new test product at intervals of $20 \mathrm{~min}$; panelist 2 started to use the test product at $t=10 \mathrm{~min}$ and used a new test product at intervals of 20 min ( 6 test products per hour, total of 12 test products for the 2 -h session). In a separate experiment, the panelists were left to decide the quantity of THS 2.2 sticks they wished to consume as well as the rate of consumption (experiments with no restraint in THS 2.2 use, ad libitum experiments, 8-15 sticks, Supplementary Table S4). The puffing intensity on the THS 2.2 by the individual panelists was measured by determination of nicotine in the mouthpiece filter of the sticks.

Each set of experiments was performed on a separate day, starting at approximately 9:30, with the background determination lasting $2 \mathrm{~h}$, followed by a 60 -min break with no 
panelists in the room and a subsequent 2-h product-use session. Each assessment type (THS 2.2 controlled consumption, THS 2.2 ad libitum, Marlboro Gold controlled consumption) had three to four replicates. Assessments with the same product (either THS 2.2 or Marlboro Gold) were grouped in the same week to avoid cross-contamination from one assessment to another and to rationalize the overall time investment. Air sampling was performed for $2 \mathrm{~h}$ starting at time $t=0 \mathrm{~min}$.

To confirm the ventilation rate in the environmentally controlled room, a tracer gas method was used according to the International Organization for Standardization (ISO) standard method ISO 16000-8 (International Organization for Standardization 2007). The room was flooded with carbon dioxide $\left(\mathrm{CO}_{2}\right)$ up to a concentration of $1 \%$, and the decay rate of $\mathrm{CO}_{2}$ was measured over $13 \mathrm{~h}$ using a non-dispersive infrared instrument (X-Stream ${ }^{\mathrm{TM}}$ Process Gas Analyzer).

The environmental room was air-washed at the maximum flow rate of filtered fresh air $\left(750 \mathrm{~m}^{3} / \mathrm{h}\right)$ for $15 \mathrm{~min}$ after the background session (this was followed by stabilization of the ventilation at 0.5 air changes $/ \mathrm{h}$ for $45 \mathrm{~min}$ prior to the productuse session) and overnight between the individual assessments. Prior to the study and at the end of each week, the walls, floor, ceiling, and furniture were washed with a water/ ethanol mixture $(80: 20, v / v)$.

\section{Determination of indoor air constituents}

A description of the methods for quantification of nicotine/3ethenylpyridine, aerosol formers (glycerin/propylene glycol), TVOC, online measurement of $\mathrm{CO}$, and online measurement of PM is given in the Supplementary Material. The rest of the analytical methods and their validation have been previously described (Gómez Lueso et al. 2018; Mottier et al. 2016). The methods used in this study were accredited according to ISO 17025 by the Swiss Accreditation Service (Accreditation number STS 0045, SAS, Bern, Switzerland, accreditation type $\mathrm{B}$ and $\mathrm{C})$.

\section{Data treatment}

All data were reported if the measured values were between the lower working range limit (LWRL) and the upper working range limit (UWRL) of the analytical method. For analytes measured below, the LWRL was reported.

The main objective of the statistical analysis was to assess the impact on the background IAQ (e.g., concentrations of measured indoor air constituents) in the environmentally controlled room when either THS 2.2 or Marlboro Gold was used under identical experimental conditions. The same statistical approach as described by Mitova et al. (2016) was applied. Details are presented in the Supplementary Materials.

A summary of the descriptive statistics for each of the measured airborne constituents per assessment type and per day is given in the Supplementary Table S3 and Table S4, respectively, together with the outcome of the statistical test for equality, summarized in Tables S5-S7.

\section{Results}

\section{Results for offline analytes}

Table 1 and Supplementary Tables S3-S4 summarize the data obtained for the measurement of all airborne constituents in the background sessions, environmental aerosol of THS 2.2, and ETS of Marlboro Gold.

In the "Residential category III" simulations, similar to the previously investigated simulated environments (Mitova et al. 2016), for both the background and THS 2.2 sessions, the indoor air concentrations of UVPM, FPM, solanesol, 3ethenylpyridine, acrolein, crotonaldehyde, acrylonitrile, and 1,3-butadiene were below the lower working range of the respective analytical methods (Table 1 and Supplementary Tables S3-S4). This was also the case for the newly measured propylene glycol, NNK, and NNN, which were found below the reporting limits of the respective analytical methods in all background and THS 2.2 sessions (Table 1 and Supplementary Tables S3-S4). Contrariwise, all these constituents were quantified in all air samples from the Marlboro Gold sessions with a relative standard deviation (RSD) below $7 \%$, except for acrolein (RSD 16\%) and propylene glycol (RSD 35\%) (Table 1 and Supplementary Tables S3-S4).

Consistent with the results for the previously investigated simulated environments (Mitova et al. 2016), nicotine, acetaldehyde, formaldehyde, benzene, isoprene, and toluene were quantified in the background and during sessions with THS 2.2, together with the newly measured TVOC (in toluene equivalents), while glycerin was present in air only in the sessions with THS 2.2 use (Table 1 and Supplementary Tables S3-S4).

Nicotine was quantified during all sessions of the study. The maximal concentrations for nicotine in all THS 2.2 sessions did not exceed $2.53 \mu \mathrm{g} / \mathrm{m}^{3}$, more than one order of magnitude below those in air enriched with ETS of Marlboro Gold (range minimum-maximum value 47.2$53.8 \mu \mathrm{g} / \mathrm{m}^{3}$; Supplementary Table S3). It is interesting to note that the residual levels of nicotine in the background of the Marlboro Gold sessions (i.e., trace levels of nicotine remaining in the environmentally controlled room after smoking of cigarettes despite the overnight air purge) were in the range of $1.66-2.40 \mu \mathrm{g} / \mathrm{m}^{3}$ (minimum-maximum for day 2-day 4 of the background for Marlboro Gold, Fig. 1, Supplementary Table S4).

Acetaldehyde was quantified under the "Residential category III" environmental conditions in the background, environmental aerosols of THS 2.2, and ETS (Table 1). The 
Table 1 Summary of measured concentrations for airborne constituents for the background, environmental aerosol of THS 2.2, and ETS of Marlboro Gold under simulated "Residential category III" environmental conditions

\begin{tabular}{|c|c|c|c|c|c|c|c|c|c|}
\hline \multirow[b]{2}{*}{ Analyte $^{\mathrm{a}}$} & & \multicolumn{2}{|c|}{ Background $\mathrm{A}^{\mathrm{b}}$} & \multicolumn{2}{|l|}{ THS $2.2^{\mathrm{b}}$} & \multicolumn{2}{|c|}{ Background C } & \multicolumn{2}{|c|}{ Marlboro Gold } \\
\hline & & Mean $^{\mathrm{c}}$ & $\mathrm{SD}^{\mathrm{d}}$ & Mean & SD & Mean & SD & Mean & SD \\
\hline UVPM & $\mu \mathrm{g} / \mathrm{m}^{3}$ & $<1.61$ & N/A & $<1.61$ & N/A & $<1.61$ & N/A & 92.9 & 2.40 \\
\hline FPM & $\mu \mathrm{g} / \mathrm{m}^{3}$ & $<0.132$ & N/A & $<0.132$ & N/A & $<0.132$ & N/A & 20.4 & 0.543 \\
\hline Solanesol & $\mu \mathrm{g} / \mathrm{m}^{3}$ & $<0.950$ & N/A & $<0.950$ & N/A & $<0.950$ & N/A & 23.9 & 0.945 \\
\hline 3-Ethenylpyridine & $\mu \mathrm{g} / \mathrm{m}^{3}$ & $<0.460$ & N/A & $<0.460$ & N/A & $<0.460$ & N/A & 10.3 & 0.612 \\
\hline Nicotine & $\mu \mathrm{g} / \mathrm{m}^{3}$ & 0.330 & 0.047 & 1.48 & 0.685 & 1.53 & 0.790 & 51.3 & 1.98 \\
\hline Acetaldehyde & $\mu \mathrm{g} / \mathrm{m}^{3}$ & $3.32^{\mathrm{e}}$ & 0.280 & 6.76 & 0.760 & $3.48^{\mathrm{e}}$ & 0.213 & 126 & 7.74 \\
\hline Acrolein & $\mu \mathrm{g} / \mathrm{m}^{3}$ & $<0.199$ & N/A & $<0.199$ & N/A & $<0.199$ & N/A & 12.4 & 1.96 \\
\hline Crotonaldehyde & $\mu \mathrm{g} / \mathrm{m}^{3}$ & $<0.116$ & N/A & $<0.116$ & N/A & $<0.116$ & N/A & 3.57 & 0.207 \\
\hline Formaldehyde & $\mu \mathrm{g} / \mathrm{m}^{3}$ & 13.0 & 2.24 & 10.8 & 1.05 & 16.0 & 1.01 & 74.9 & 4.44 \\
\hline Acrylonitrile & $\mu \mathrm{g} / \mathrm{m}^{3}$ & $<0.652$ & N/A & $<0.652$ & N/A & $<0.652$ & N/A & 5.28 & 0.309 \\
\hline Benzene & $\mu \mathrm{g} / \mathrm{m}^{3}$ & 1.00 & 0.127 & 0.943 & 0.119 & 0.713 & 0.107 & 14.9 & 0.964 \\
\hline 1,3-Butadiene & $\mu \mathrm{g} / \mathrm{m}^{3}$ & $<2.57$ & N/A & $<2.57$ & N/A & $<2.57$ & N/A & 17.6 & 0.783 \\
\hline Isoprene & $\mu \mathrm{g} / \mathrm{m}^{3}$ & 8.65 & 0.614 & 9.85 & 1.32 & 8.96 & 1.26 & 173 & 8.53 \\
\hline Toluene & $\mu \mathrm{g} / \mathrm{m}^{3}$ & 2.68 & 0.280 & 2.32 & 0.306 & 1.52 & 0.303 & 26.7 & 2.07 \\
\hline TVOC & $\mu \mathrm{g} / \mathrm{m}^{3}$ & 20.4 & 0.632 & 22.2 & 0.933 & 34.1 & 12.4 & 479 & 19.4 \\
\hline Glycerin & $\mu \mathrm{g} / \mathrm{m}^{3}$ & $<6.23$ & N/A & 13.3 & 3.39 & $<6.23$ & N/A & 10.0 & 1.33 \\
\hline Propylene glycol & $\mu \mathrm{g} / \mathrm{m}^{3}$ & $<28.6$ & N/A & $<28.6$ & N/A & 33.8 & 22.4 & 64.2 & 22.6 \\
\hline $\mathrm{NNK}$ & $\mu \mathrm{g} / \mathrm{m}^{3}$ & $<2.07 \mathrm{E}-04$ & N/A & $<2.07 \mathrm{E}-04$ & N/A & $<2.07 \mathrm{E}-04$ & N/A & $8.90 \mathrm{E}-03$ & $2.72 \mathrm{E}-04$ \\
\hline NNN & $\mu \mathrm{g} / \mathrm{m}^{3}$ & $<1.56 \mathrm{E}-04$ & N/A & $<1.56 \mathrm{E}-04$ & N/A & $<1.56 \mathrm{E}-04$ & N/A & $1.52 \mathrm{E}-03$ & $1.07 \mathrm{E}-04$ \\
\hline $\mathrm{PM}_{1}$ & $\mu \mathrm{g} / \mathrm{m}^{3}$ & $<11.0$ & N/A & $<11.0$ & N/A & $<11.0$ & N/A & 687 & 343 \\
\hline $\mathrm{PM}_{2.5}$ & $\mu \mathrm{g} / \mathrm{m}^{3}$ & $<11.0$ & N/A & $<11.0$ & N/A & $<11.0$ & N/A & 688 & 343 \\
\hline $\mathrm{CO}$ & ppm & 0.495 & 0.052 & 0.444 & 0.037 & 0.327 & 0.038 & 2.88 & 1.34 \\
\hline NO & ppb & 35.8 & 10.7 & 23.9 & 4.19 & 8.71 & 1.53 & 67.2 & 32.2 \\
\hline $\mathrm{NO}_{\mathrm{x}}$ & $\mathrm{ppb}$ & 42.2 & 11.4 & 30.0 & 5.00 & 14.2 & 0.927 & 75.1 & 32.6 \\
\hline
\end{tabular}

${ }^{a}$ For the descriptive statistics, refer to Supplementary Table S3 and Table S4

${ }^{\mathrm{b}}$ Summary of mean and standard deviation for the experiments with THS 2.2 controlled consumption and the respective background; for mean and standard deviation for the experiments with THS 2.2 ad libitum consumption refer to supplementary Table S3

"All means measured below LWRL are displayed as " $<$ [value for LWRL]," except for NNK, NNN, PM 1 , and PM 2.5 displayed as " $<$ [value for LLOQ]"

${ }^{\mathrm{d}} \mathrm{SD}$, standard deviation

${ }^{\mathrm{e}}$ The mean for acetaldehyde is below LWRL $\left(3.91 \mu \mathrm{g} / \mathrm{m}^{3}\right)$

concentrations in ETS of Marlboro Gold were more than one order of magnitude higher than those in background air and environmental aerosols of THS 2.2 (range minimum-maximum: $<3.91-5.16 \mu \mathrm{g} / \mathrm{m}^{3}$ for background, $5.92-10.9 \mu \mathrm{g} / \mathrm{m}^{3}$ for THS 2.2, $106-140 \mu \mathrm{g} / \mathrm{m}^{3}$ for Marlboro Gold; Supplementary Table S3). Formaldehyde was present in all sessions at similar concentrations for background and THS 2.2 aerosols and well above those levels in ETS of Marlboro Gold (range minimum-maximum: $10.0-21.1 \mu \mathrm{g} / \mathrm{m}^{3}$ for Background, 9.95-20.9 $\mu \mathrm{g} / \mathrm{m}^{3}$ for THS 2.2, 66.4-82.1 $\mu \mathrm{g} /$ $\mathrm{m}^{3}$ for Marlboro Gold; Supplementary Table S3).

Under "Residential category III" environmental conditions, results close to those of formaldehyde were obtained for benzene, isoprene, toluene, and TVOC (in toluene equivalents), and the concentrations of these compounds were similar in the background and THS 2.2 sessions, while they increased by at least one order of magnitude when Marlboro Gold was used indoors (Table 1, Supplementary Table S3).

The concentrations of glycerin in all background sessions were below the working range of the method, while similar concentrations of glycerin were quantified in all sessions with THS 2.2 and Marlboro Gold consumption (Table 1, Supplementary Table S3).

The $95 \%$ confidence interval of the difference in mean concentrations for formaldehyde, benzene, toluene, and TVOC in the THS 2.2 sessions and corresponding background sessions was included within the method critical difference, while the $95 \%$ confidence interval of the mean differences for nicotine, acetaldehyde, isoprene, and glycerin was larger than the method critical difference 
Fig. 1 Comparison of data for nicotine measurements in background, environmental aerosol of THS 2.2 and ETS of Marlboro Gold under simulated "Residential category III" environmental condition. A, THS 2.2 controlled and respective background; B, THS 2.2 ad libitum and respective background; C, Marlboro Gold and respective background

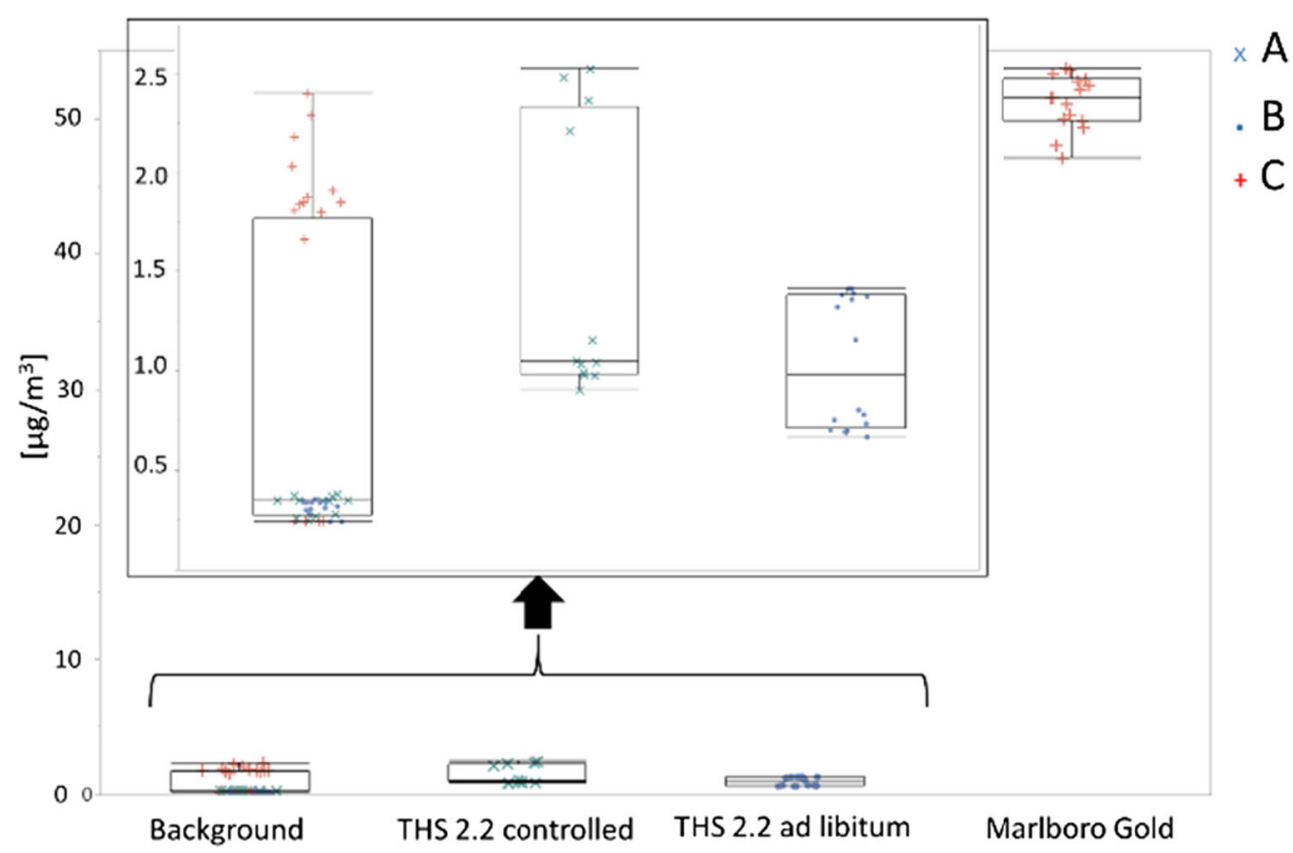

(Supplementary Tables S5-S6). The differences in means for nicotine, acetaldehyde, formaldehyde, benzene, isoprene, toluene, TVOC, and glycerin between the background and Marlboro Gold sessions were statistically significant (Supplementary Table S7).

\section{Results for TVOC qualitative analyses}

TVOC gives a general picture for the presence of nonpolar and slightly polar VOC (boiling point in the range $50-260{ }^{\circ} \mathrm{C}$ ) in the indoor environment, and it is defined as the sum of VOCs that elute between and including nhexane $\left(\mathrm{C}_{6}\right)$ and $\mathrm{n}$-hexadecane $\left(\mathrm{C}_{16}\right)$ on a non-polar column (International Organization for Standardization 2011). The ISO norm (International Organization for Standardization 2011) requires identification of the compounds with concentrations in toluene equivalents above $2 \mu \mathrm{g} / \mathrm{m}^{3}$. The qualitative profiles included in the $\mathrm{C}_{6}-\mathrm{C}_{16}$ window (International Organization for Standardization 2011) of the sessions with THS 2.2 use, and their corresponding backgrounds were very similar in the range above $2 \mu \mathrm{g} / \mathrm{m}^{3}$ (Fig. 2).

In fact, the same compounds were identified in the $\mathrm{C}_{6}-\mathrm{C}_{16}$ window as required by the ISO standard (International Organization for Standardization 2011) (Supplementary Table S8) in both the THS 2.2 sessions and the respective background.

The only differences were due to different peak intensities resulting in turn in slightly different toluene equivalents for the TVOC values. In contrast, qualitative differences were evident for the chromatographic profiles when comparing sessions with ETS to both background air and air enriched with environmental aerosol of THS 2.2 (Fig. 2 ). The list of compounds identified by comparison with authentic standards in the $\mathrm{C}_{6}-\mathrm{C}_{16}$ window above $2 \mu \mathrm{g} / \mathrm{m}^{3}$ for the sessions with THS 2.2 use and the corresponding background sessions are summarized in Supplementary Table S8 (and also in Fig. 2).

\section{Results for online analytes}

The online trace of $\mathrm{PM}_{1}$ and $\mathrm{PM}_{2.5}$ monitored during the background, THS 2.2, and Marlboro Gold sessions are displayed in Fig. 3.

The $\mathrm{PM}_{1}$ and $\mathrm{PM}_{2.5}$ online signals measured by DustTrack for ETS showed several maxima. During the session with Marlboro Gold, each cigarette smoked led to an increase in the PM levels, which subsequently resulted in a peak. Altogether, 12 peaks were monitored corresponding to the smoking of 12 cigarettes (one cigarette consumed every 10 min during the 120-min session). The ventilation removed only partially the indoor PM, and the initial levels were not recovered, with a progressively upward, saw-tooth-like trend being observed. In contrast, the online measurements of background air and environmental aerosol of THS 2.2 both showed a similar pattern: a flat line was recorded throughout the sampling period, and the measured $\mathrm{PM}_{1}$ and $\mathrm{PM}_{2.5}$ levels were below the quantification limit of the method (Fig. 3).

Figure 4 and Supplementary Fig. S3-S4 show a representative plot of the $\mathrm{CO}, \mathrm{NO}$, and $\mathrm{NO}_{\mathrm{x}}$ online measurements, respectively, during the background, THS 2.2, and Marlboro Gold sessions.

Similar to the online measurements of PM, the signals for $\mathrm{CO}, \mathrm{NO}$, and $\mathrm{NO}_{\mathrm{x}}$ of ETS showed 12 maxima, reflecting the 
Fig. 2 Comparison of the TDGC-MS trace for TVOC measurements in $\mathrm{C}_{6}-\mathrm{C}_{16}$ window for background (a), environmental aerosol of THS 2.2 (b), and ETS of Marlboro Gold (c).

Compounds (Supplementary

Table S8): 1-butanol (1), benzene (2), propylene glycol (3), toluene (4), ethylbenzene (6), 1,3butanediol (7), benzaldehyde (10), unknown (probably alcanoic acid) (11), benzyl alcohol (12), nonanal (13), 2-phenoxyethanol (15) $x 10^{5}$
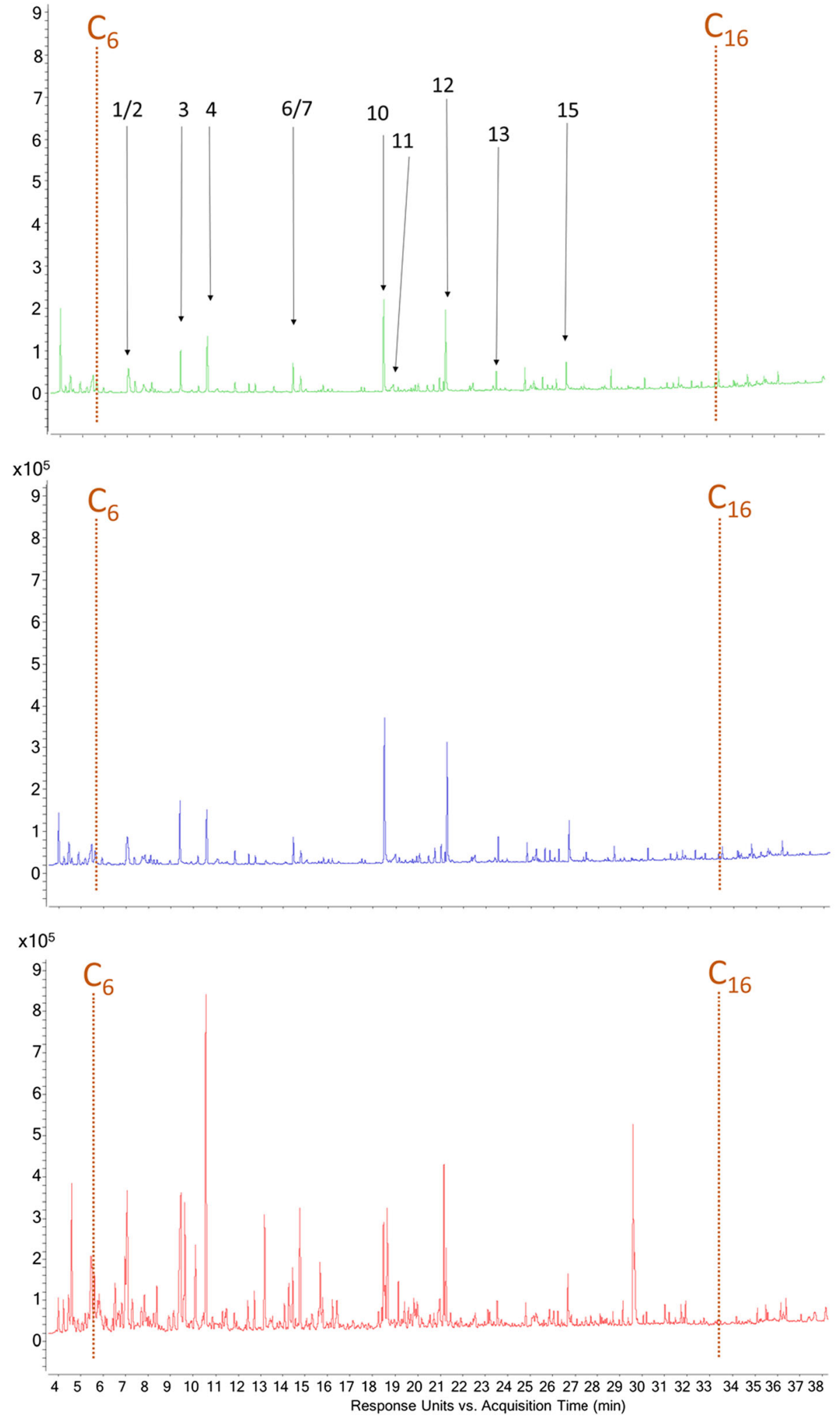

(a)

(b)

(c)

smoking schedule of the panelists (Fig. 4, Supplementary Fig. S3-S4). In contrast, a flat line was obtained for the environmental aerosol resulting from the use of THS 2.2 and online measurements of background (Fig. 4, Supplementary Fig. S3-
S4). The $\mathrm{CO}, \mathrm{NO}$, and $\mathrm{NO}_{\mathrm{x}}$ levels during the THS 2.2 session did not exceed the background levels (Table 1, Supplementary Table S3). 


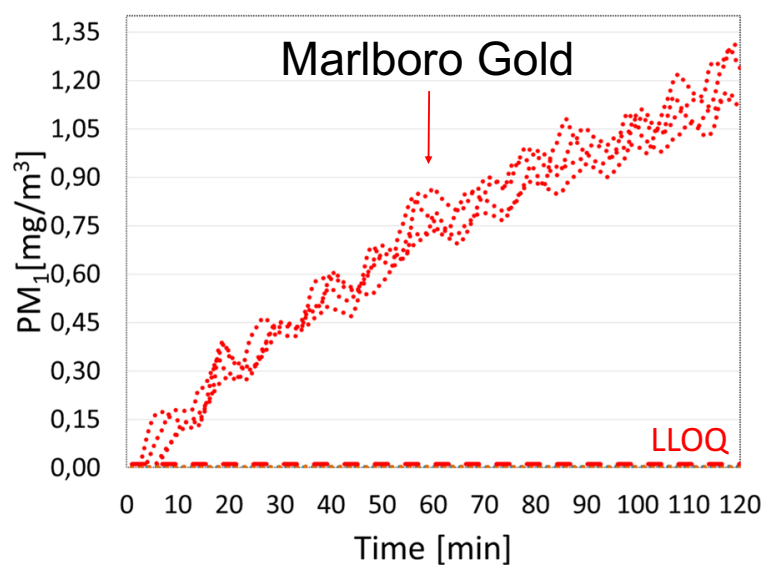

(a)

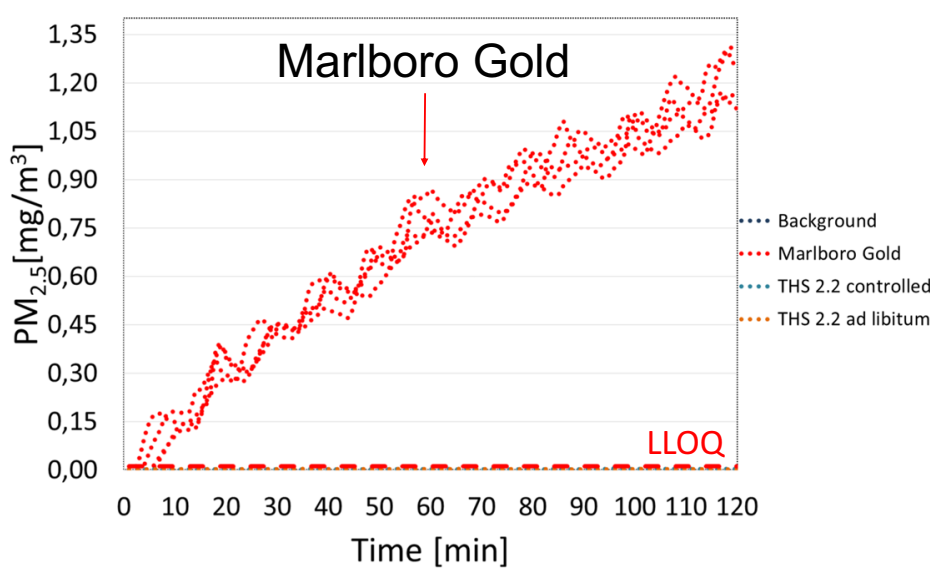

(b)

Fig. 3 Online measurements for $\mathrm{PM}_{1}(\mathbf{a})$ and $\mathrm{PM}_{2.5}$ (b) under simulated "Residential category III" environmental condition. The trace for $\mathrm{PM}_{1}$ and $\mathrm{PM}_{2.5}$ are below the LLOQ $\left(11.0 \mu \mathrm{g} / \mathrm{m}^{3}\right)$ for background, THS 2.2 controlled and THS 2.2 ad libitum

The $95 \%$ confidence interval of the mean difference for the $\mathrm{CO}, \mathrm{NO}$, and $\mathrm{NO}_{\mathrm{x}}$ measurements in all THS 2.2 sessions and corresponding backgrounds as well as Marlboro Gold sessions and corresponding backgrounds did not include 0 , thereby demonstrating statistically significant differences between all samples (Supplementary Tables S5-S7). Careful inspection of the data (Table 1 and Supplementary Tables S3-S4) indicated that the concentrations of $\mathrm{CO}, \mathrm{NO}$, and $\mathrm{NO}_{\mathrm{x}}$ in the sessions with THS 2.2 were lower than background $\mathrm{CO}, \mathrm{NO}$, and $\mathrm{NO}_{\mathrm{x}}$ levels, respectively. In contrast, during the Marlboro Gold session, the levels of $\mathrm{CO}, \mathrm{NO}, \mathrm{NO}_{\mathrm{x}}, \mathrm{PM}_{1}$, and $\mathrm{PM}_{2.5}$ concentrations were found to be substantially higher than the background levels.

\section{Results obtained for measurements of nicotine in filters}

The user's mouth level exposure (MLE) was estimated from the amount of nicotine analyzed in mouthpiece filters recovered from the used THS 2.2 HeatSticks during the study (Supplementary Table S9). The mouthpiece filter analysis for the estimation of a HeatStick user's MLE is a method proposed in a published study (Poget et al. 2017). This determination requires pre-defined linear calibration regression equations calculated between nicotine yields in mainstream aerosols and corresponding nicotine amounts in mouthpiece filters. In the present study, calibrations were derived from analytical puffing of HeatSticks conducted in the laboratory under five different smoking machine regimes (Supplementary Table S9) simulating different possible human usage behavior.

The distribution pattern of the nicotine retained in the mouthpiece filters for the different THS 2.2 sessions is summarized in the Supplementary Figs. S5-S6.

Nicotine quantified in air was attributed to exhaled nicotine. However, due to nicotine retention in the body, users' MLE to nicotine is not representative of the exhaled nicotine amounts. Therefore, nicotine retention in the body was derived from MLE and nicotine quantified in air. Data and calculations of estimated nicotine retention in the body derived from estimated MLE and nicotine quantified in air are presented in Supplementary Table S10.

\section{Discussion}

\section{Simulation of high-load residential environment}

Studies on the environmental aerosol generated by using THS 2.2 in the "real-world" present the challenge that the nonspecificity of most smoking-related and IAQ markers, and the low levels of environmental emissions of THS 2.2 make it difficult to distinguish the impact of the THS 2.2 environmental aerosol from those of confounding sources of indoor pollution (Kauneliene et al. 2018). Therefore, the previously reported studies (Mitova et al. 2016) and the present assessment were performed using simulations of "real-world" conditions under strictly controlled experimental conditions. For comparative studies, this approach has a major advantage: VOC and particle filters can be used to minimize and control additional environmental sources of indoor air constituents. This approach is reported in other studies on heated tobacco products (Forster et al. 2018; Ichitsubo and Kotaki 2018; Nelson et al. 1998; Tricker et al. 2009). In contrast, several investigations have been performed in indoor environments with limited control of the environmental parameters and without air filtration (Frost-Pineda et al. 2008; Protano et al. 2016, 2017) or even in real-life environments (Prodanchuk et al. 2017; Ruprecht et al. 2017; Schober et al. 2018).

Important considerations in simulations of real-life environments include the assessment of the representativeness of 
Fig. 4 Online measurements for CO under simulated "Residential category III" environmental condition. Comparison of $\mathrm{CO}$ traces for a background (BKG A1-BKG A3) vs THS 2.2 controlled consumption (THS 2.2 control 1-3), b background (BKG B1-BKG B4) vs THS 2.2 ad libitum consumption (THS 2.2 ad lib 1-4), c background (BKG C1BKG C4) vs Marlboro Gold controlled consumption (MLG 1-4)

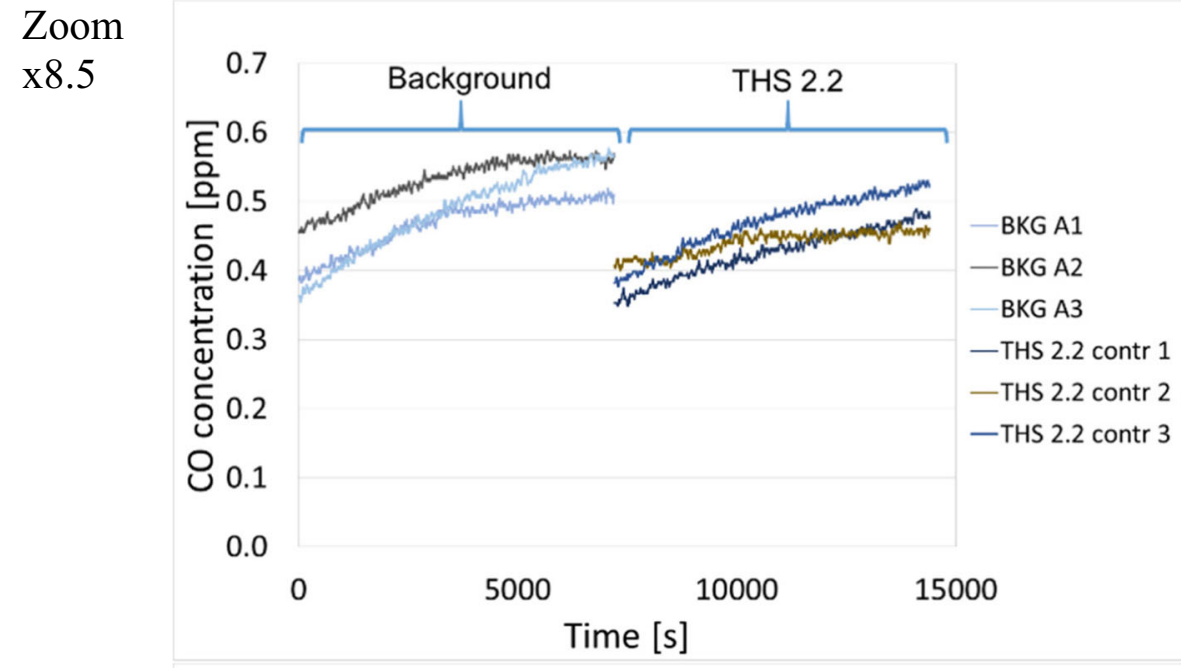

(a)

Zoom $\mathrm{x} 8.5$

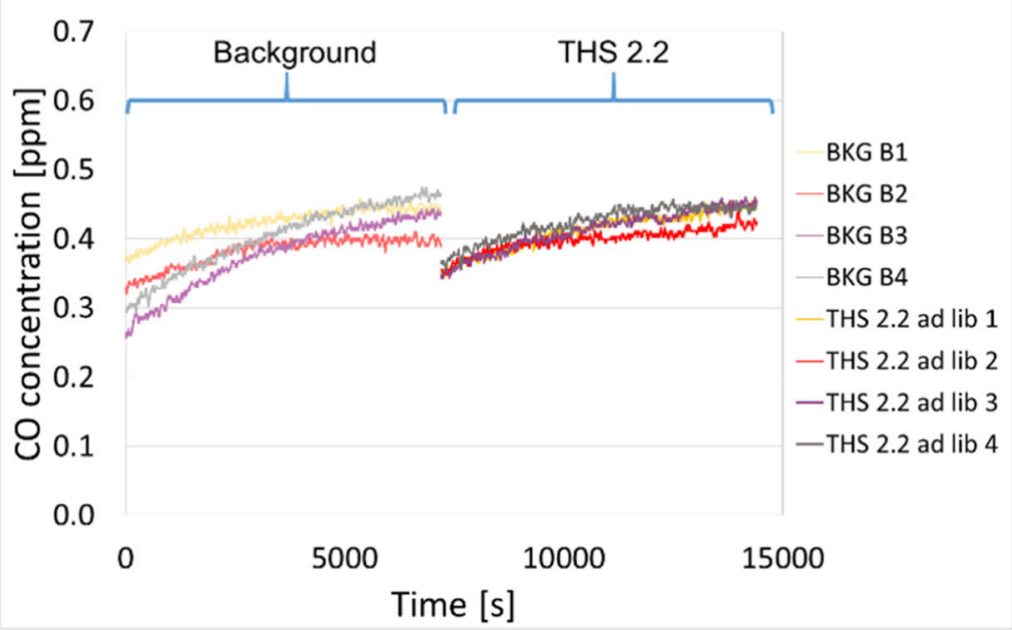

(b)

(c)

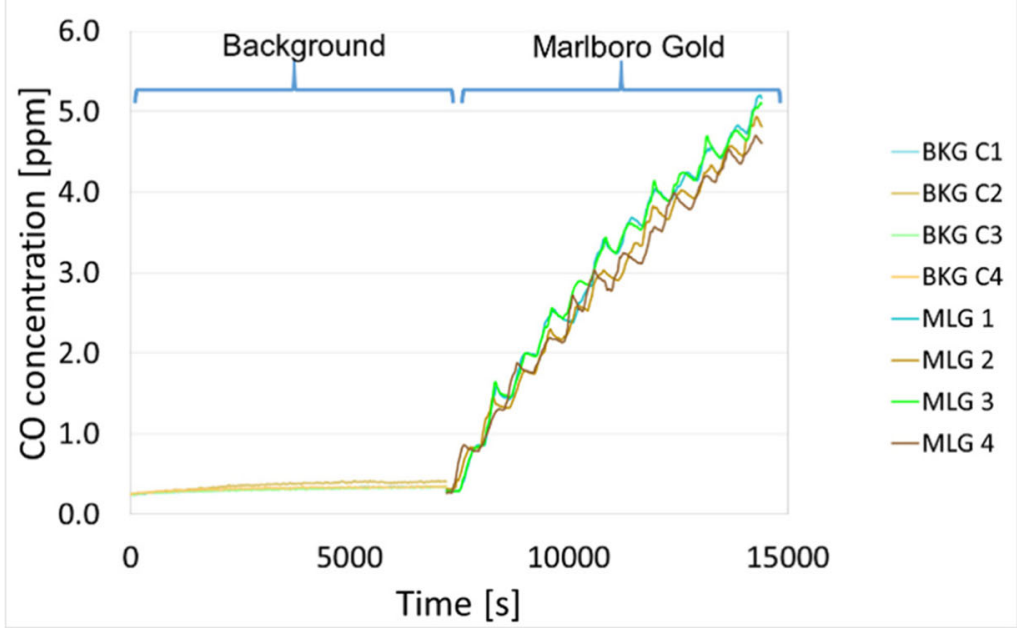

the selected conditions and whether the reported concentrations of airborne pollutants are comparable to those reported in the literature for similar environments.

Most existing residential buildings still rely on natural ventilation, which is based on the use of temperature differences and wind with facade grills in combination with exhausts (e.g., corridors, toilets), infiltration caused by air leakage and openable windows. In the EN 15251 standard (European Committee for Standardization 2007), the recommended ventilation for residential environments conforming to a moderate 
level of occupants' expectations (anticipated 30\% dissatisfaction; residential category III environment) corresponds to 0.5 air changes/h. These values are the same as the Japanese ventilation recommendations for residential buildings (Ministry of Land, Infrastructure, Transport and Tourism of Japan nd). In the USA, the recommended ventilation levels for residential buildings are slightly higher, with the lowest level being 0.7 air changes/h (American Society of Heating, Refrigerating and Air-Conditioning Engineers 2016).

The number of tobacco products consumed in an indoor environment is currently not specified explicitly in any norm. Previously, the ventilation for smoking lounges, considered as specific indoor environments where all occupants are smokers, was calculated based on a smoking rate of three cigarettes/person/h or, for so-called heavy-smoker lounges, of six cigarettes/person/h (Glantz and Schick 2004).

Taking all these arguments into account, to reproduce highload indoor conditions corresponding to low aeration with high consumption of tobacco products, ventilation rates of 0.5 air changes $/ \mathrm{h}$ with six sticks/h were selected as representative for residential conditions.

The degree of typicality of the selected simulation conditions could be evaluated by comparison with the data for real-world concentrations of ETS markers in homes where smoking occurred. The reported real-world values for residential environments for all listed airborne constituents were several times below those quantified for the sessions with Marlboro Gold, except for those for benzene and toluene, which were at a similar level (Supplementary Table S11). Therefore, comparison with literature data suggests that the concentrations of ETS markers reached in this study for the assessments with Marlboro Gold were indeed representative of high-load smoking environments (Supplementary Table S11). In addition, as foreseen due to the lowering of the ventilation rates, the indoor concentrations of all measured constituents during the assessments with Marlboro Gold were higher in comparison with the previously reported concentrations for the other simulated environments (Mitova et al. 2016).

\section{Characterization of the environmental aerosol of THS 2.2 in a high-load residential environment}

The analyses of the data indicated different qualitative and quantitative patterns for the environmental aerosol of THS 2.2 emitted during indoor use of THS 2.2 under simulated conditions of a high-load residential environment compared with those of the ETS of cigarettes. In fact, the outcome of this study further substantiated the conclusion that the use of THS 2.2 in indoor environments resulted not only in considerable reductions of pollutants in comparison with cigarette smoking but also, more importantly, in very similar concentrations of measured indoor air constituents to those found in the absence of tobacco product use.
No quantifiable to negligible increases (within the uncertainty of the analytical methods) of the typical particulatephase markers for ETS, either measured online $\left(\mathrm{PM}_{1}\right.$ and $\mathrm{PM}_{2.5}$ ) or as non-specific particulate-phase markers (such as UVPM and FPM) or as a specific particulate-phase marker for tobacco products (such as solanesol), were determined for the THS 2.2 sessions (Table 1 and Supplementary Tables S3-S4). The results for UVPM and FPM were expected since the aerosol of THS 2.2 contains constituents formed mainly by distillation from the tobacco matrix with low concentrations of thermal degradation products (Schaller et al. 2016), and only very low to negligible levels of organic residue might be released in the indoor environment during product use. Contrariwise, the smoking of cigarettes, used as positive control, led to a strong increase of UVPM and FPM markers (Table 1, Supplementary Tables S3-S4). Furthermore, the low levels of solanesol would be considered likely due to the retention of this compound in the body of the THS 2.2 user (>50\%) (Baker and Dixon 2006). The results of a study in passenger car interiors also showed almost no impact on the median number concentrations of microscale particles, particularly $\mathrm{PM}_{2.5}$, but the particle number concentrations of nanoscale PM (25-300 nm) increased in all car interiors (Schober et al. 2018). Conversely, some other studies on PM during indoor use of THS 2.2 indicated somewhat different results (Protano et al. 2016, 2017; Ruprecht et al. 2017). Indeed, Ruprecht et al. (2017) reported an increase in $\mathrm{PM}_{1}$ and $\mathrm{PM}_{2.5}$ together with $\mathrm{PM}_{10}$ above the background levels during indoor use of THS 2.2, but these increases were lower (less than $2 \%$ ) than that measured for cigarettes. Particle number concentrations for nano-sized PM and those above $0.3 \mu \mathrm{m}$ (Ruprecht et al. 2017) and for PM in the 5.6-560 nm range (Protano et al. 2016, 2017) were measured, and in both studies, a brief, low-level increase above the background concentrations during use of THS 2.2 was found. Determining the reason for the differences in some observations of the different studies is rendered difficult by the fact that the equipment used in the current study differed from that used by the other research groups (e.g., no measurement of PM less than $100 \mathrm{~nm}$ was performed by us to verify the results on particle number concentrations of ultrafine suspended PM) (Protano et al. 2016, 2017; Ruprecht et al. 2017; Schober et al. 2018). Apart from this, a plausible explanation for the differences in measurements of suspended PM could be as follows. The mainstream aerosol of THS 2.2 contains respirable liquid-based PM $(<2.5 \mu \mathrm{m})$ mainly composed of water and glycerin (Pratte et al. 2017, 2018; Schaller et al. 2016), thus being an aerosol with characteristics of mist. These aerosol droplets dissipate quickly in the indoor environment after release, as evaluated by machine smoking (less than $1 \mathrm{~min}$ ). It is plausible to assume that the water evaporates in the airborne liquid particles emitted during the consumption of THS 2.2, leaving behind the less volatile glycerin in droplets largely reduced in size, probably 
in the nanoscale range. If the concentrations of the aerosol droplets exhaled during the THS 2.2 sessions had been above $5 \mu \mathrm{g} / \mathrm{m}^{3}$ (the validated detection limit of DustTrak) and with sizes above $100 \mathrm{~nm}$, they would certainly have been measured by the DustTrak instrument. Future studies using additional equipment for measurement of PM (e.g., by using equipment for measurement of nanoscale suspended PM as well as simultaneous measurement of $\mathrm{PM}_{\mathrm{x}}$ ( $\mathrm{x}$ in the range $<100 \mathrm{~nm}-10 \mu \mathrm{m}$ ) at different distances from the users) will provide further insight into the nature, concentration, size, and numbers of PM released during indoor use of THS 2.2. It is important to recognize that currently, due to lack of sufficient evidence for adverse effects on health, no specific air quality guidelines for $\mathrm{PM}_{1}$ or $\mathrm{PM}$ below 100 nm exist (Cassee et al. 2013).

Furthermore, Ruprecht et al. (2017) described low-level emissions of organic residue associated with PM during indoor use of THS 2.2 and identified the constituents as $\mathrm{C}_{20}-\mathrm{C}_{38}$ n-alkanes, $\mathrm{C}_{10}-\mathrm{C}_{30}$ fatty acids, and the anhydrosugar levoglucosane. The most abundant of the n-alkanes (hentriacontane and heptacosane) and fatty acids (palmitic and linoleic acids) are common plant metabolites, which were identified in the PM of the mainstream aerosol of THS 2.2 (Food and Drug Administration 2017); therefore, their release at low to negligible levels in the indoor environment during THS 2.2 use is plausible. Due to the negligible levels of PM monitored during THS 2.2 sessions in the previous studies (Mitova et al. 2016) and the current investigation, we have not performed further examination of the PM data described by Ruprecht et al. (2017).

Sixteen of the 18 studied gas-phase ETS markers in the THS 2.2 sessions did not exceed those found in the background (Table 1, Supplementary Tables S1, S3-S4). In particular, 3ethenylpyridine, a specific gas-phase marker of ETS formed by thermal decomposition of nicotine during tobacco combustion (Jenkins et al. 2000), was not detected during the THS 2.2 assessments and neither were the two cancerogenic TSNAs (NNN and NNK). Consistent with these results, 3-ethenylpyridine was not detected in the study of Schober et al. (2018).

Under conditions of a simulated high-load residential environment, it seemed plausible that the IAQ room background itself and/or the emissions from exhaled breath, skin, and personal belongings of the panelists influenced the indoor concentrations of formaldehyde, benzene, isoprene, toluene, TVOC, $\mathrm{CO}, \mathrm{NO}$, and $\mathrm{NO}_{\mathrm{x}}$. These observations corroborate well with findings from previous studies (Mitova et al. 2016). Indeed, the airborne concentrations of formaldehyde, benzene, toluene, $\mathrm{CO}, \mathrm{NO}$, and $\mathrm{NO}_{\mathrm{x}}$ in the sessions with THS 2.2 use were slightly below those for the background, suggesting general within-day (background vs. THS 2.2 use) and between-day variations (replicates on different days) of the background levels of these compounds (Table 1 and Supplementary Tables S3-S4).

Caponnetto et al. (2018) analyzed the CO levels in the exhaled breath of THS 2.2 users and cigarette smokers and found, in contrast to cigarettes, no increase of $\mathrm{CO}$ levels after THS 2.2 use. Conclusions similar to those of the present study were drawn by Prodanchuk et al. (2017) for CO and formaldehyde. In that study, during the consumption of 80 sticks of THS 2.2 by 20 volunteers in a bar where 80 volunteers were present, only a slight increase in CO and formaldehyde air concentrations was measured, explained by the researchers as the normal background drift caused by human presence and recreational activities. Likewise, Schober et al. (2018) found the airborne concentrations of $\mathrm{CO}$, benzene, toluene, and formaldehyde in the interiors of cars $\left(2-5 \mathrm{~m}^{3}, 2\right.$ sticks of THS 2.2 in $20 \mathrm{~min}$ ) within the range of background pollution. Contrariwise, Ruprecht et al. (2017) described an increase in the formaldehyde concentrations during indoor use of 10-14 sticks of THS 2.2, which was interpreted based on simultaneous indoor vs. outdoor measurements of the formaldehyde concentrations, but which lacked additional baseline control of the indoor levels without any tobacco product use. The latter experiments were performed in the living room of an apartment occupied by habitual smokers, which, like any indoor environment, has higher indoor levels of formaldehyde compared with the outdoor levels due to emissions from furniture and furnishings, fabrics, and personal care products and due to normal metabolism of the panelists (Salthammer et al. 2010). Outdoor air has formaldehyde concentrations typically around $1-4 \mu \mathrm{g} / \mathrm{m}^{3}$ due to fast photo-oxidation of formaldehyde in sunlight to carbon dioxide (World Health Organization 2010). In contrast, the indoor concentrations of formaldehyde in the European Union in non-smoking environments is typically at median levels of $26 \pm 6 \mu \mathrm{g} / \mathrm{m}^{3}$ (90th percentile \pm standard deviation, $59 \pm 7 \mu \mathrm{g} / \mathrm{m}^{3}$ ) (Kotzias et al. 2005). Thus, the difference in the result for formaldehyde in the current study and in Ruprecht's study might result from the fact that background measurement was only partially performed in the latter study (Ruprecht et al. 2017).

In the present study, a slight increase above the background levels was found for isoprene and TVOC concentrations (Table 1, inside the method critical difference for TVOC and outside for isoprene; see also Supplementary Tables S5-S7). When comparing the TVOC traces in the THS 2.2 sessions with those of their respective backgrounds (Fig. 2), a high similarity was noted. In fact, the same compounds were identified in the $\mathrm{C}_{6}-\mathrm{C}_{16}$ window (Supplementary Table S8) in both the THS 2.2 sessions and their respective backgrounds. The only differences were due to different peak intensities, resulting in turn in slightly different toluene equivalents for the TVOC values. It should be noted that TVOC levels provide a general picture for the presence of VOCs in the indoor environment, which would also include emissions from the indoor environment, people, and their personal belongings. It is generally accepted that the lower the TVOC concentrations in indoor air are, the lower the risk is that any of these 
VOCs will contribute to a perception of discomfort. At TVOC concentrations of $22.2 \mu \mathrm{g} / \mathrm{m}^{3}$ of toluene equivalents for the sessions with THS 2.2 use (background at $20.4 \mu \mathrm{g} / \mathrm{m}^{3}$ ), the TVOC levels were well below the comfort threshold of $200 \mu \mathrm{g} / \mathrm{m}^{3}$ (Molhave 1991). During the background and THS 2.2 sessions, 17 compounds were detected above $2 \mu \mathrm{g} /$ $\mathrm{m}^{3}$ in the TVOC trace (Supplementary Table S8, Fig. 2). They belong to the group of aromatic hydrocarbons, alcohols, carbonyls, and cyclic volatile methyl siloxanes. These compounds were reported for different indoor environments with no use of any tobacco products (Brown et al. 1994; Ishizaka et al. 2018; Jurvelin 2003). For example, nonanal is a straight chain aldehyde associated with human presence and is considered to derive from ozone reaction with skin lipids (Kwak et al. 2015). It is important to note that propylene glycol, in contrast to e-cigarettes, is not an aerosol former for the THS 2.2 aerosol. Small quantities are used for the preparation of the flavor mixture; therefore, it is quantified at concentrations of approximately $300-500 \mu \mathrm{g} / \mathrm{stick}$ (unpublished data). At retention rates of $92 \%$ in the body of the users (St Helen et al. 2016), only negligible airborne concentrations of propylene glycol are probable, which fits well with the results of the TVOC analysis and the dedicated method for measurement of propylene glycol (Table 1 and Supplementary Tables S3S4).

Likewise, Schober et al. (2018) measured the concentrations of 19 VOCs, including propylene glycol, during the THS 2.2 use in cars and found the levels of the measured compounds, except for those for nicotine, in the range of the control where no consumption of any tobacco product occurred.

Human presence influences the indoor levels of isoprene. In fact, isoprene, the major hydrocarbon found in human breath, is a marker for human presence (Giannoukos et al. 2014), with generation rates per occupant estimated at 200 $300 \mu \mathrm{g} / \mathrm{h}$ (Hodgson and Levin 2003). In addition, as the main source of impact on IAQ when THS 2.2 is consumed is exhalation of non-retained mainstream aerosol constituents by the THS 2.2 user, the data on the mainstream aerosol of THS 2.2 give a good estimation of what might be expected in the THS 2.2 environmental aerosol. Indeed, lower levels of isoprene in the mainstream aerosol of THS 2.2 were measured compared with formaldehyde, which was found at background levels during the same experiment (isoprene $2.35 \mu \mathrm{g} /$ stick vs. formaldehyde $5.53 \mu \mathrm{g} /$ stick) (Schaller et al. 2016). Considering these points, it would seem plausible that isoprene and TVOC levels increased slightly above the background during THS 2.2 sessions not due to the product use, but either as a result of contribution of the panelists themselves (isoprene, partially TVOC), or the general variations in the background (partially TVOC). In reality, it was difficult to properly aerate the IAQ room after the background session and remove all human-related VOCs, as it never remained empty due to the presence of technical staff checking the equipment and preparing trapping before and between the sessions.

To better understand the general variations in the background levels of the measured airborne constituents caused by residual emissions of building materials and infiltration of outdoor air, and in order to also properly evaluate the impact of the emissions from the panelists, a study was designed and conducted (manuscript in preparation). An example for the results with isoprene is given in Supplementary Fig. S7.

In good agreement with the previous studies for simulated residential environments with a ventilation rate of 1.2 air changes/h (Mitova et al. 2016), the measured concentrations of nicotine and acetaldehyde during the THS 2.2 sessions were higher than the background levels. This was also the case for the newly measured glycerin, with the average concentrations determined during all THS 2.2 sessions exceeding the concentrations measured in the background sessions when panelists did not use THS 2.2 (Table 1 and Supplementary Tables S3-S4). This was to be expected, taking into account the concentrations of these constituents in the mainstream aerosol of THS 2.2 (acetaldehyde, $219 \mu \mathrm{g} / \mathrm{stick}$; glycerin, $4.63 \mathrm{mg} / \mathrm{stick}$; nicotine, $1.32 \mathrm{mg} /$ stick) (Schaller et al. 2016).

The number of the consumed HeatSticks influenced only to certain extends the concentrations of the airborne constituents (Supplementary Table S4). For example, the lowest average concentrations of nicotine were measured during the experiments with total of eight consumed sticks (mean $0.693 \mu \mathrm{g} / \mathrm{m}^{3}$, Supplementary Table S4). However, the highest nicotine concentrations were not measured during the session with the highest number of sticks (total of 15 , mean $1.39 \mu \mathrm{g} / \mathrm{m}^{3}$ ) but during one of the sessions with total of 12 consumed sticks (mean $2.40 \mu \mathrm{g} / \mathrm{m}^{3}$; Supplementary Table S4). Most likely the specific consumption behavior of the volunteer panelists influenced the indoor concentrations of the airborne compounds, and this observation warrants further research.

Glycerin was typically not measured in the background sessions $(<\mathrm{LWRL})$; owing to the average retention in the body of the users of $84 \%$ (St Helen et al. 2016), low airborne glycerin concentrations were expected during indoor use of THS 2.2, and glycerin was quantified at $13.3 \mu \mathrm{g} / \mathrm{m}^{3}$.

The concentrations of nicotine during all the sessions with THS 2.2 use was relatively low (mean $1.48 \mu \mathrm{g} / \mathrm{m}^{3}$, Table 1 , Supplementary Table S3). As indicated by the comparison of the theoretical nicotine concentration in air, an estimate based on the MLE, and the measured airborne nicotine (Supplementary Table S10), the retention by the panelists was in the range of $96.7-99.4 \%$. These levels of retention were in agreement with literature data (Baker and Dixon 2006; Feng et al. 2007). However, the low experimental concentrations of nicotine in the environmental aerosol of THS 2.2 might also be explained to some extent by adsorption of nicotine on the surfaces, and this hypothesis merits further investigation. 
In addition, the concentrations of acetaldehyde during all the THS 2.2 sessions were also in the low ppb range (mean $6.76 \mu \mathrm{g} / \mathrm{m}^{3}$, Table 1, Supplementary Table S3). Literature data indicate $90 \%$ retention of the inhaled acetaldehyde (Baker and Dixon 2006). However, it must be mentioned that approximately half of the measured acetaldehyde concentrations were not due to THS 2.2 usage. Indeed, acetaldehyde is ubiquitous in all indoor environments (Kotzias et al. 2005). Acetaldehyde is naturally contained in exhaled breath (Amann et al. 2014). The levels measured during the background experiments were in the range of $<3.91-5.16 \mu \mathrm{g} / \mathrm{m}^{3}$ (Supplementary Table S3), which is below the median acetaldehyde concentrations of $10-20 \mu \mathrm{g} / \mathrm{m}^{3}$ found in European residences (Kotzias et al. 2005). This collaborates well with the expected low background levels, which can be attributed to the use of filtered air and the requirements for the study (e.g., no use of perfumes and perfumed cosmetics). At these low background levels of acetaldehyde, it is feasible to quantify the increase of this compound during indoor use of THS 2.2.

Similar to the results for formaldehyde, Ruprecht et al. (Ruprecht et al. 2017) found an increase in the acetaldehyde concentrations during indoor use of 10-14 sticks of THS 2.2. Contrariwise, Schober et al. (2018) reported acetaldehyde concentrations during THS 2.2 use in cars within the range of background pollution with no smoking activity. Further studies should be undertaken to verify if it is possible that an increase in acetaldehyde above the background levels could be quantifiable in real-life environments and not only in evaluations in controlled experiments with filtered air.

The concentrations of 23 out of 24 measured indoor air constituents in the Marlboro Gold sessions, used as a positive control during the study, were higher than the background levels and those observed during the THS 2.2 sessions (Table 1, Supplementary Tables S3-S4), which replicates the findings for the other simulated environments (Mitova et al. 2016). The exception was glycerin, which was quantified at similar levels in the Marlboro Gold and THS 2.2 sessions.

The compounds clearly attributed to the use of THS 2.2 are acetaldehyde, glycerin, and nicotine. The indoor environments were generally free from the presence of nicotine and glycerin but contained low levels of acetaldehyde. However, as nicotine is readily absorbed onto surfaces and later desorbed and re-emitted (Hodgson et al. 1996), residual amounts could be carried by the panelists. Indeed, nicotine was detected during most of the background sessions (Table 1, Supplementary Tables S3-S4). Nevertheless, it should be emphasized that cross-contamination clearly occurred from one session to another where Marlboro Gold was smoked, with a notable increase in the nicotine background levels from day 1 to day 4 of the experiments (Fig. 5). In contrast, this was not the case for the sessions with THS 2.2, where this trend was not noticed (Fig. 5).

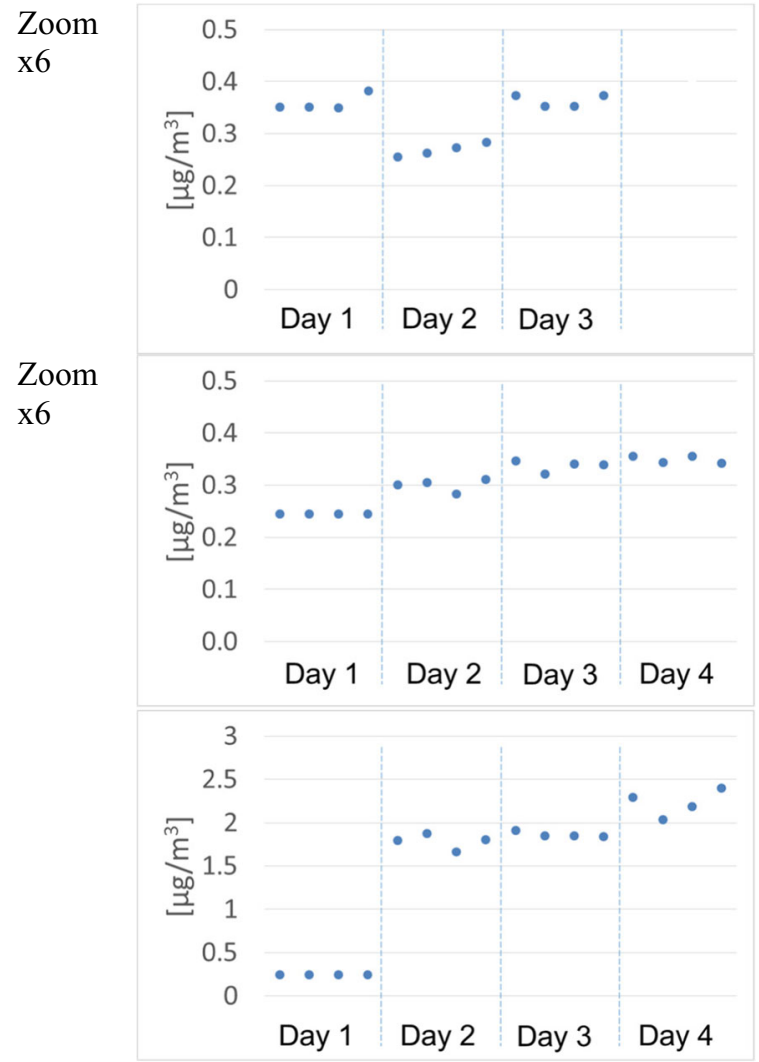

(a)

(b)

(c)

Fig. 5 Concentrations of nicotine in different replicates of the background sessions. a Background for THS 2.2 controlled consumption. b Background for THS 2.2 ad libitum consumption. c Background for Marlboro Gold controlled consumption

On average, a smoker retains approximately $60-80 \%$ of PM, $80-100 \%$ of nicotine, $55-80 \%$ of CO, $100 \%$ of NO, $90-100 \%$ of carbonyls, $84-97 \%$ of NNN, and $63-84 \%$ of NNK on inhalation of mainstream cigarette smoke into the respiratory tract (Baker and Dixon 2006; Feng et al. 2007). Retention of individual compounds is influenced by several factors, including mouth-spill, inhalation volume, depth of inhalation, and breath-hold. Acetaldehyde and the tobacco-specific constituent nicotine are both known to occur in the exhaled breath of cigarette smokers (Baker and Dixon 2006; Feng et al. 2007). The presence of very low levels of nicotine and glycerin was also demonstrated for the exhaled breath of e-cigarette users, with estimated retention of $49 \% \geq 99 \%$ (average $93.8 \%$ ) and $4 \% \geq 99 \%$ (average $84.4 \%$ ) for nicotine and glycerin, respectively (St Helen et al. 2016). No similar data are available for the retention of the mainstream aerosol components of THS 2.2, but in general, a similar retention for the same constituents is expected. Thus, it is plausible that when THS 2.2 is used, the source of impact on IAQ is exhalation of non-retained mainstream aerosol constituents by the THS 2.2 user. In addition, the current study also took into account the negligible emissions of THS 
2.2, which occurred during the pre-heating phase and after completion of the consumption, as well as differences in the consumption behaviors of the volunteer panelists resulting from differences in mouth-spill, inhalation volume, depth of inhalation, and breath-hold.

\section{Air quality standards and guidelines}

The sheer quantity as well as the privacy of residential spaces makes it difficult to enforce IAQ standards. Raising public awareness and information are key to providing safer residential environments, because the vast majority of potential indoor pollution risks must be identified and managed by the occupants themselves (Kotzias et al. 2005). The American Society of Heating, Refrigerating and Air-Conditioning Engineers (American Society of Heating, Refrigerating and Air-Conditioning Engineers 2016) defines IAQ as acceptable if the air contains no known contaminants at harmful concentrations as determined by cognizant authorities and with which a substantial majority ( $80 \%$ or more) of the people exposed do not express dissatisfaction. Thus, guideline values for key pollutants can be applied by judging the acceptability of IAQ in a building (Kotzias et al. 2005).

The acetaldehyde concentrations measured during the use of THS 2.2 under "Residential category III" simulations (Table 1, Supplementary Tables S3-S4) were below the minimal risk level for chronic exposure $\left(140 \mu \mathrm{g} / \mathrm{m}^{3}\right)$ listed by the California Office of Environmental Health Hazard Assessment (California Office of Environmental Health Hazard Assessment 2016) and the proposed exposure limit of $200 \mu \mathrm{g} / \mathrm{m}^{3}$ in the European Union (Kotzias et al. 2005). The WHO (World Health Organization 2010) considers acetaldehyde as an air pollutant of potential interest for regulation.

The nicotine concentrations measured during the use of THS 2.2 (Table 1, Supplementary Tables S3-S4) were well below the indicative occupational exposure limit values of $500 \mu \mathrm{g} / \mathrm{m}^{3}$ in the European Union (European Agency for Safety and Health at Work 2006) and the permissible exposure limit of $500 \mu \mathrm{g} / \mathrm{m}^{3}$ defined by the U.S. Occupational Safety and Health Administration (Occupational Safety and Health Administration 1978). The maximum allowable contaminant levels specified in occupational exposure standards apply for healthy adult individuals, controlled exposures, and normal workweek exposure duration (typically $40 \mathrm{~h}$ per week), with provisions for simultaneous exposures to more than one regulated contaminant. Consequently, the maximum allowed concentration values are usually one to three orders of magnitude higher than those measured in residences buildings. Clearly, neither the approach nor the levels are applicable for general indoor air risk management, although occupational exposure limit values divided by 10 (to allow for a much longer exposure time and heterogeneous target population) have been sometimes used in the absence of an alternative, more effective method as indicative levels in non-industrial indoor spaces as well (Kotzias et al. 2005). However, even if comparing with such an extrapolated $50 \mu \mathrm{g} / \mathrm{m}^{3}$ limit, the levels of airborne nicotine during the indoor use of THS 2.2 remain at least one order of magnitude below.

The non-toxic substance glycerin was measured up to $13.3 \mu \mathrm{g} / \mathrm{m}^{3}$ (mean, Table 1, Supplementary Tables S3-S4). This compound is not usually part of air quality regulations and is present only in workplace exposure guidelines. For example, the American Conference of Governmental Industrial Hygienists (American Conference of Governmental Industrial Hygienists 2001) sets a guideline level at $10,000 \mu \mathrm{g} / \mathrm{m}^{3}$, a concentration more than 750 times above that measured during THS 2.2 consumption.

Today, it is recognized that indoors, there is no safe level of exposure to ETS emitted by cigarettes (World Health Organization 2017). Indeed, during the experiments with the smoking of Marlboro Gold in a high-load-simulated residential environment, the indoor concentrations of several constituents exceeded the exposure levels set forth by cognizant authorities. Thus, the indoor concentrations of $\mathrm{PM}_{2.5}$, acrolein, acrylonitrile, benzene, 1,3-butadiene, and $\mathrm{NO}_{2}$ (if the value for $\mathrm{NO}_{\mathrm{x}}$ is considered) all exceeded the minimal risk level for chronic exposure of the California Office of Environmental Health Hazard Assessment (California Office of Environmental Health Hazard Assessment 2016). Moreover, during cigarette smoking, the indoor concentrations for $\mathrm{PM}_{2.5}$ and benzene were significantly above the guideline exposure levels set forth by the WHO (World Health Organization 2010) and the European Union (European Commission 2018) and those for formaldehyde in the European Union (Kotzias et al. 2005).

\section{Conclusions}

Under simulated "Residential category III" environmental conditions, only two compounds listed as HPHCs (nicotine and acetaldehyde) and one specific compound (the aerosol former glycerin) were attributable to the indoor use of THS 2.2. The quantified concentrations of the three airborne compounds during indoor use of THS 2.2 in the high-load-simulated residential environment studies were below the harmful levels defined by cognizant authorities. Thus, normal hygienic measures, such as regular aeration of the residential spaces, would lead to efficient control of these low to negligible levels of pollution. Furthermore, the evaluation of the concentrations of PM, VOCs, and semi-volatile markers of ETS during simulations with THS 2.2 consumption showed that the environmental aerosol of THS 2.2 is very different from the ETS emitted during the smoking of cigarettes. 
In conclusion, the use of THS 2.2 in an indoor environment, where norms for indoor exposure in terms of adequate ventilation are respected, does not adversely affect the overall IAQ.

Acknowledgments We thank Bruno Chassot for the assistance with sample collection; the Central Analytical Labs of R\&D of PMI for assistance with nicotine in filter analyses; the General Services of PMI for their continuous support; Julia Carroll, Elena Scotti, and Nicholas Karoglou for the comments that greatly improved the manuscript.

Funding Philip Morris International is the sole source of funding and sponsor of this research.

\section{Compliance with ethical standards}

Conflict of interest All authors were Philip Morris International employees at the time the study was conducted.

Open Access This article is distributed under the terms of the Creative Commons Attribution 4.0 International License (http:// creativecommons.org/licenses/by/4.0/), which permits unrestricted use, distribution, and reproduction in any medium, provided you give appropriate credit to the original author(s) and the source, provide a link to the Creative Commons license, and indicate if changes were made.

\section{References}

Amann A, Costello BL, Miekisch W, Schubert J, Buszewski B, Pleil J, Ratcliffe N, Risby T (2014) The human volatilome: volatile organic compounds (VOCs) in exhaled breath, skin emanations, urine, feces and saliva. J Breath Res 8:034001. https://doi.org/10.1088/1752$7155 / 8 / 3 / 034001$

American Conference of Governmental Industrial Hygienists (ACGIH) (2001) Threshold limit value for glycerin mist. American Conference of Governmental Industrial Hygienists

American Society of Heating, Refrigerating and Air-Conditioning Engineers (ASHRAE) (2016) ANSI/ASHRAE Standard 62.22016. Ventilation for acceptable indoor air quality in residential buildings. American Society of Heating, Refrigerating and AirConditioning Engineers Inc., Atlanta

Baker RR, Dixon M (2006) The retention of tobacco smoke constituents in the human respiratory tract. Inhal Toxicol 18:255-294. https://doi. org/10.1080/08958370500444163

Baker RR, Proctor CJ (1990) The origins and properties of environmental tobacco smoke. Environ Int 16:231-245. https://doi.org/10.1016/ 0160-4120(90)90117-0

Bekki K, Inaba Y, Uchiyama S, Kunugita N (2017) Comparison of chemicals in mainstream smoke in heat-not-burn tobacco and combustion cigarettes. J UOEH 39:201-207. https://doi.org/10.7888/ juoeh.39.201

Brown SK, Sim MR, Abramson MJ, Gray CN (1994) Concentrations of volatile organic compounds in indoor air - a review. Indoor Air 4: 123-134. https://doi.org/10.1111/j.1600-0668.1994.t01-2-00007.x

California Office of Environmental Health Hazard Assessment (OEHHA) (2016) Acute, 8-hour and chronic reference exposure level (REL) summary. California Office of Environmental Health Hazard Assessment. https://oehha.ca.gov/air/general-info/oehhaacute-8-hour-and-chronic-reference-exposure-level-rel-summary. Accessed 21 December 20182018
Caponnetto P, Maglia M, Prosperini G, Busà B, Polosa R (2018) Carbon monoxide levels after inhalation from new generation heated tobacco products. Respir Res 19:164. https://doi.org/10.1186/s12931018-0867-z

Cassee FR, Héroux M-E, Gerlofs-Nijland ME, Kelly FJ (2013) Particulate matter beyond mass: recent health evidence on the role of fractions, chemical constituents and sources of emission. Inhal Toxicol 25:802-812. https://doi.org/10.3109/08958378.2013. 850127

Daisey JM (1999) Tracers for assessing exposure to environmental tobacco smoke: what are they tracing? Environ Health Perspect 107(Suppl 2):319-327. https://doi.org/10.1289/ehp.99107s2319

European Agency for Safety and Health at Work (2006) Directive 2006/15/EC - Indicative occupational exposure limit values. Off J Eur Union. https://osha.europa.eu/en/legislation/directives/ commission-directive-2006-15-ec. Accessed 21 December 2018

European Commission (2018) Air quality standards. European Commission. http://ec.europa.eu/environment/air/quality/standards. htm. Accessed 21 December 20182018

European Committee for Standardization (2007) European Standard EN 15251. Indoor environmental input parameters for design and assessment of energy performance of buildings addressing indoor air quality, thermal environment, lighting and acoustics. European Committee for Standardization, Brussels

Feng S, Plunkett SE, Lam K, Kapur S, Muhammad R, Jin Y, Zimmermann M, Mendes P, Kinser R, Roethig HJ (2007) A new method for estimating the retention of selected smoke constituents in the respiratory tract of smokers during cigarette smoking. Inhal Toxicol 19:169-179. https://doi.org/10.1080/08958370601052022

Food and Drug Administration (FDA) (2012) Harmful and potentially harmful constituents in tobacco products and tobacco smoke; established list

Food and Drug Administration (FDA) (2017) Philip Morris Products S.A. modified risk tobacco product (MRTP) applications. https://www. fda.gov/tobaccoproducts/labeling/marketingandadvertising/ ucm546281.htm\#2. Accessed 21 December 20182018

Forster M, McAughey J, Prasad K, Mavropoulou E, Proctor C (2018) Assessment of tobacco heating product THP1.0. Part 4: characterisation of indoor air quality and odour. Regul Toxicol Pharmacol 93: 34-51. https://doi.org/10.1016/j.yrtph.2017.09.017

Frost-Pineda K, Zedler BK, Liang Q, Roethig HJ (2008) Environmental tobacco smoke (ETS) evaluation of a third-generation electrically heated cigarette smoking system (EHCSS). Regul Toxicol Pharmacol 52:118-121. https://doi.org/10.1016/j.yrtph.2008.06.007

Giannoukos S, Brkic B, Taylor S, France N (2014) Monitoring of human chemical signatures using membrane inlet mass spectrometry. Anal Chem 86:1106-1114. https://doi.org/10.1021/ac403621c

Glantz S, Schick S (2004) Implications of ASHRAE'S guidance on ventilation for smoking-permitted areas. ASHRAE J 46:54-59

Gómez Lueso M, Mitova MI, Mottier N, Schaller M, Rotach M, GoujonGinglinger CG (2018) Development and validation of a method for quantification of two tobacco-specific nitrosamines in indoor air. $\mathrm{J}$ Chromatogr A 1580:90-99. https://doi.org/10.1016/j.chroma.2018. 10.037

Hodgson AT, Levin H (2003) Volatile organic compounds in indoor air: a review of concentrations measured in North America since 1990. Lawrence Berkeley National Laboratory, San Francisco

Hodgson AT, Daisey JM, Mahanama KRR, Ten Brinke J, Alevantis LE (1996) Use of volatile tracers to determine the contribution of environmental tobacco smoke to concentrations of volatile organic compounds in smoking environments. Environ Int 22:295-307. https:// doi.org/10.1016/0160-4120(96)00015-3

Ichitsubo H, Kotaki M (2018) Indoor air quality (IAQ) evaluation of a novel tobacco vapor (NTV) product. Regul Toxicol Pharmacol 92: 278-294. https://doi.org/10.1016/j.yrtph.2017.12.017 
International Organization for Standardization (ISO) (2007) ISO 160008. Indoor air - part 8: determination of local mean ages of air in buildings for characterizing ventilation conditions. International Organization for Standardization, Geneva

International Organization for Standardization (ISO) (2011) ISO 16000-6 Determination of volatile organic compounds in indoor and test chamber air by active sampling on Tenax TA sorbent, Thermal desorption and gas chromatography using MS or MS-FID. International Organization for Standardization, Geneva

Ishizaka TD, Kawashima A, Hishida N, Hamada N (2018) Measurement of total volatile organic compound (TVOC) in indoor air using passive solvent extraction method. Air Qual Atmos Health 12:173-187. https://doi.org/10.1007/s11869-018-0639-4

Jenkins RA, Guerin MR, Tomkins BA (2000) The chemistry of environmental tobacco smoke: composition and measurement, 2nd edn. Lewis Publishers Inc, Boca Raton

Jurvelin JA (2003) Personal exposures to volatile organic compounds and carbonyls: relationship to microenvironment concentrations and analysis of sources. Academic dissertation, National Public Health Institute

Kauneliene V, Meisutovic-Akhtarieva M, Martuzevicius D (2018) A review of the impacts of tobacco heating system on indoor air quality versus conventional pollution sources. Chemosphere 206:568-578. https://doi.org/10.1016/j.chemosphere.2018.05.039

Kotzias D, Koistinen K, Kephalopoulos S, Carrer P, Maroni M, Schlitt $\mathrm{CH}$, Jantunen M, Cochet CH, Kirchner S, Lindvall T, McLaughlin J, Molhave L (2005) The INDEX Project - critical appraisal of the setting and implementation of indoor exposure limits in the EU

Kwak J, Geier BA, Fan M, Gogate SA, Rinehardt SA, Watts BS, Grigsby CC, Ott DK (2015) Detection of volatile organic compounds indicative of human presence in the air. J Sep Sci 38:2463-2469. https:// doi.org/10.1002/jssc.201500261

Mallock N, Böss L, Burk R, Danziger M, Welsch T, Hahn H, Trieu HL, Hahn J, Pieper E, Henkler-Stephani F, Hutzler C, Luch A (2018) Levels of selected analytes in the emissions of "heat not burn" tobacco products that are relevant to assess human health risks. Arch Toxicol 92:2145-2149. https://doi.org/10.1007/s00204-0182215-y

Ministry of Land, Infrastructure, Transport and Tourism (n.d.) Building Standard Law of Japan, Building Standard Law Enforcement Order and Notifications of Japan. http://www.mlit.go.jp/english/housing bureau/law/03.pdf. Accessed 21 December 2018

Mitova MI, Campelos PB, Goujon-Ginglinger CG, Maeder S, Mottier N, Rouget EGR, Tharin M, Tricker AR (2016) Comparison of the impact of the Tobacco Heating System 2.2 and a cigarette on indoor air quality. Regul Toxicol Pharmacol 80:91-101. https://doi.org/10. 1016/j.yrtph.2016.06.005

Molhave L (1991) Volatile organic compounds, indoor air quality and health. Indoor Air 1:357-376. https://doi.org/10.1111/j.1600-0668. 1991.00001.x

Mottier N, Tharin M, Cluse C, Crudo JR, Lueso MG, Goujon-Ginglinger CG, Jaquier A, Mitova MI, Rouget EGR, Schaller M, Solioz J (2016) Validation of selected analytical methods using accuracy profiles to assess the impact of a Tobacco Heating System on indoor air quality. Talanta 158:165-178. https://doi.org/10.1016/j.talanta. 2016.05.022

Nelson PR, Kelly SP, Conrad FW (1998) Studies of environmental tobacco smoke generated by different cigarettes. J Air Waste Manage Assoc 48:336-344. https://doi.org/10.1080/10473289.1998. 10463685

Occupational Safety and Health Administration (1978) Occupational health guideline for nicotine. Occupational Health Guidelines for Chemical Hazards

Poget L, Campelos P, Jeannet C, Maeder S (2017) Development of models for the estimation of mouth level exposure to aerosol constituents from a heat-not-burn tobacco product using mouthpiece analysis. Beiträge zur Tabakforschung Int/Contrib Tobacco Res 27:42-64. https://doi.org/10.1515/cttr-2017-0005

Pope CA, Brook RD, Burnett RT, Dockery DW (2010) How is cardiovascular disease mortality risk affected by duration and intensity of fine particulate matter exposure? An integration of the epidemiologic evidence. Air Qual Atmos Health 4:5-14. https://doi.org/10.1007/ s11869-010-0082-7

Pratte P, Cosandey S, Goujon Ginglinger C (2017) Investigation of solid particles in the mainstream aerosol of the Tobacco Heating System THS2.2 and mainstream smoke of a 3R4F reference cigarette. Hum Exp Toxicol 36:1115-1120. https://doi.org/10.1177/ 0960327116681653

Pratte P, Cosandey S, Goujon Ginglinger C (2018) Innovative methodology based on the thermo-denuder principle for the detection of combustion-related solid particles or high boiling point droplets: application to 3R4F cigarette and the Tobacco Heating System THS 2.2. J Aerosol Sci 120:52-61. https://doi.org/10.1016/j. jaerosci.2017.12.011

Prodanchuk MG et al (2017) Potential risk assessment of the electrically heated tobacco system (EHTS) use. Problem articles 1-2 5-14

Protano C, Manigrasso M, Avino P, Sernia S, Vitali M (2016) Secondhand smoke exposure generated by new electronic devices (IQOS(R) and e-cigs) and traditional cigarettes: submicron particle behaviour in human respiratory system. Ann Ig 28:109-112. https:// doi.org/10.7416/ai.2016.2089

Protano C, Manigrasso M, Avino P, Vitali M (2017) Second-hand smoke generated by combustion and electronic smoking devices used in real scenarios: ultrafine particle pollution and age-related dose assessment. Environ Int 107:190-195. https://doi.org/10.1016/j. envint.2017.07.014

Royal College of Physicians (2016) Nicotine without smoke: tobacco harm reduction. RCP. https://www.rcplondon.ac.uk/projects/ outputs/nicotine-without-smoke-tobacco-harm-reduction-0. Accessed 21 December 20182018

Ruprecht AA, de Marco C, Saffari A, Pozzi P, Mazza R, Veronese C, Angellotti G, Munarini E, Ogliari AC, Westerdahl D, Hasheminassab S, Shafer MM, Schauer JJ, Repace J, Sioutas C, Boffi R (2017) Environmental pollution and emission factors of electronic cigarettes, heat-not-burn tobacco products, and conventional cigarettes. Aerosol Sci Technol 51:674-684. https://doi.org/ 10.1080/02786826.2017.1300231

Salthammer T, Mentese S, Marutzky R (2010) Formaldehyde in the indoor environment. Chem Rev 110:2536-2572. https://doi.org/10. $1021 / \mathrm{cr} 800399 \mathrm{~g}$

Schaller JP, Keller D, Poget L, Pratte P, Kaelin E, McHugh D, Cudazzo G, Smart D, Tricker AR, Gautier L, Yerly M, Reis Pires R, le Bouhellec S, Ghosh D, Hofer I, Garcia E, Vanscheeuwijck P, Maeder S (2016) Evaluation of the Tobacco Heating System 2.2. Part 2: chemical composition, genotoxicity, cytotoxicity, and physical properties of the aerosol. Regul Toxicol Pharmacol 81(Suppl 2):S27-S47. https:// doi.org/10.1016/j.yrtph.2016.10.001

Schober W, Fembacher L, Frenzen A, Fromme H (2018) Abschlussbericht zum Forschungsprojekt Schadstoffbelastung von Pkw-Innenräumen beim Rauchen unterschiedlicher Rauchsysteme. Bayerisches Landesamt für Gesundheit und Lebensmittelsicherheit

Smith MR, Clark B, Ludicke F, Schaller JP, Vanscheeuwijck P, Hoeng J, Peitsch MC (2016) Evaluation of the Tobacco Heating System 2.2. Part 1: description of the system and the scientific assessment program. Regul Toxicol Pharmacol 81(Suppl 2):S17-S26. https://doi. org/10.1016/j.yrtph.2016.07.006

St Helen G, Havel C, Dempsey DA, Jacob P 3rd, Benowitz NL (2016) Nicotine delivery, retention and pharmacokinetics from various electronic cigarettes. Addiction 111:535-544. https://doi.org/10. 1111/add.13183

Tricker AR, Schorp MK, Urban HJ, Leyden D, Hagedorn HW, Engl J, Urban M, Riedel K, Gilch G, Janket D, Scherer G (2009) 
Comparison of environmental tobacco smoke (ETS) concentrations generated by an electrically heated cigarette smoking system and a conventional cigarette. Inhal Toxicol 21:62-77. https://doi.org/10. 1080/08958370802207334

van Erp AM, Kelly FJ, Demerjian KL, Pope CA, Cohen AJ (2011) Progress in research to assess the effectiveness of air quality interventions towards improving public health. Air Qual Atmos Health 5:217-230. https://doi.org/10.1007/s11869-010-0127-y

World Health Organization (WHO) (2010) WHO guidelines for indoor air quality: selected pollutants. https://www.ncbi.nlm.nih.gov/ pubmed/23741784. Accessed 21 December 20182018

World Health Organization (WHO) (2014) Work in progress in relation to articles 9 and 10 of the WHO FCTC. World Health Organization.
http://apps.who.int/gb/fctc/PDF/cop6/FCTC_COP6_14-en.pdf. Accessed 21 December 20182018

World Health Organization (WHO) (2017) WHO report on the global tobacco epidemic, 2017: monitoring tobacco use and prevention policies. World Health Organization. http://apps.who.int/iris/ bitstream/handle/10665/255874/9789241512824-eng.pdf. Accessed 21 December 2018

Publisher's note Springer Nature remains neutral with regard to jurisdictional claims in published maps and institutional affiliations. 